\title{
Análise comparativa de protocolos para extração de DNA genômico em Prosopis juliflora (Sw.) DC
}

\author{
Luiz Henrique Tolentino Santos ${ }^{1,4}$ \\ Cibelle Santos Dias ${ }^{2,4}$ \\ Jardyelle Carvalho Lima ${ }^{4}$ \\ Messulan Rodrigues Meira ${ }^{2,4}$ \\ Carlos Bernard Moreno Cerqueira Silva ${ }^{1,2,3,4 *}$

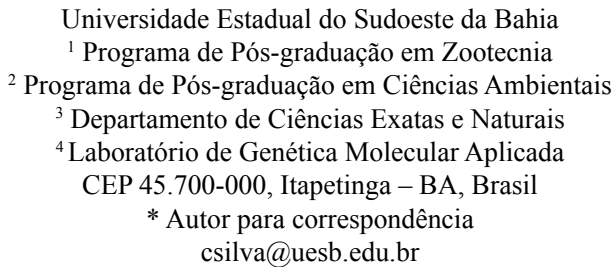

Submetido em $18 / 08 / 2020$

Aceito para publicação em 14/12/2020

\section{Resumo}

Objetivou-se comparar a eficiência entre sete protocolos adaptados para a extração de DNA genômico da espécie Prosopis juliflora (Sw). DC. Os protocolos utilizados tiveram como base em seus tampões: SDS 10\%; CTAB 5\%; Sorbitol, CTAB 3\% e Sorbitol; SDS 0,7\% e NaCl; CTAB 2\%; CTAB 2\% e NaCl 1,4M. Em todos os testes, eliminou-se o uso de $\beta$-mercaptoetanol, nitrogênio líquido, proteinase K e RNAses. As amostras consistiram de primórdios folhiares de cada espécime em triplicata. A quantidade e a qualidade do DNA extraído foram avaliadas através de eletroforese em gel de agarose a 1\% e da leitura das absorbâncias em espectrofotômetro. Para as reações de amplificação, utilizou-se o iniciador ISSR. Entre os tampões de extração testados, os de SDS $10 \%$, de CTAB 5\% e de CTAB 3\% e Sorbitol foram os mais eficientes para $P$. juliflora. Desses três protocolos, o CTAB 3\% e Sorbitol apresentou melhor nível de pureza apesar da menor quantidade de DNA (123 ng/ $\mu \mathrm{L})$ se comparado aos tampõs de SDS 10\% e de CTAB 5\% (312 e $321 \mathrm{ng} / \mu \mathrm{L}$, respectivamente, e com alto teor de contaminantes). Conclui-se que é possível o uso de protocolos de extração sem aditivos nocivos à saúde e com menor custo no processo de extração.

Palavras-chave: Ácidos nucleicos; Algaroba; Genética molecular; PCR

\section{Abstract}

Comparative analysis of protocols for genomic DNA extraction in Prosopis juliflora (Sw.) DC. The objective of the present research was to compare the efficiency among seven protocols adapted for the extraction of genomic DNA from the species Prosopis juliflora (Sw.) DC. The protocols used were based on their buffers: SDS $10 \%$, CTAB 5\%, Sorbitol, CTAB 3\% and Sorbitol, SDS $0.7 \%$ and $\mathrm{NaCl}, \mathrm{CTAB} 2 \%, \mathrm{CTAB} 2 \%$ and $\mathrm{NaCl}$ 
1.4M. In all tests, the use of $\beta$-mercaptoethanol, liquid nitrogen, proteinase $\mathrm{K}$ and RNAses was eliminated. The samples consisted of leaf primordia in each specimen in triplicate. The quantity and quality of the extracted DNA were evaluated by electrophoresis in $1 \%$ agarose gel and by reading the absorbances in a spectrophotometer. For amplification reactions, the ISSR primer was used. Among the tested extraction buffers, SDS $10 \%$, CTAB $5 \%$ and CTAB 3\%, and Sorbitol were the most efficient for P. juliflora. Of these three protocols, CTAB 3\% and Sorbitol showed a better level of purity despite the lower amount of DNA $(123 \mathrm{ng} / \mu \mathrm{L})$ compared to $10 \% \mathrm{SDS}$ and 5\% CTAB buffers (312 and $321 \mathrm{ng} / \mu \mathrm{L}$, respectively, and high content of contaminants). We conclude that it is possible to use extraction protocols without additives that are harmful to human health and at a lower cost in the extraction process.

Key words: Algaroba; Molecular genetics; Nucleic acids; PCR

\section{Introdução}

Prosopis juliflora (Sw.) DC é, conforme The Legume Phylogeny Working Group (LPWG, 2017), uma espécie arbórea, da família das leguminosas (Leguminoseae, subfamília Caesalpinoideae). Originária da região tropical andina e bem adaptada às regiões semi-áridas de baixa precipitação. Popularmente conhecida como algaroba ou algarobeira, essa espécie possui diversos usos bem como importância econômica (DOS SANTOS; DIODATO, 2017), entre eles: a alimentação humana e de animais, a produção de madeira e a recuperação de áreas degradadas. Pode, ainda, ser utilizada, entre outras possibilidades, como inseticida, analgésico, anti-helmíntico, antibiótico, probióticos e como suplemento nutricional (AHIRWAL et al., 2017; HENCIYA et al., 2017; DHIVYA et al., 2018).

Embora a espécie possua muito potencial de uso pelo ser humano e estudos de diveridade genética sejam o ponto de partida para se efetivar ações de conservação e de melhoramento de espécies com potencial econômico (LOPES et al., 2011; BESSEGA et al., 2018; FALEIRO et al., 2018), pouco se conhece quanto à diversidade genética de $P$. juliflora. Para estudos dessa natureza, faz-se necessária a obtenção de ácidos nucleicos, em quantidades e qualidades que possibilitem a amplificação do material genômico e a seleção de iniciadores potenciais (MICHEL-LÓPEZ et al., 2013).

O processo de extração de DNAé parte fundamental em estudos moleculares, sendo sua eficiência diretamente relacionado à pureza, à quantidade e à qualidade do material genômico obtido (DA ROCHA et al., 2017). A extração de DNA de tecidos vegetais requer protocolos específicos devido à presença de metabólitos secundários e polissacarídeos comuns a cada espécie. Portanto, a adequação de protocolos é indispensável para obtenção de DNA puro e íntegro, e para melhor eficiência na amplificação do material genômico em estudos moleculares (OLIVEIRA et al., 2017; DIAS et al., 2018).

Pelas razões apresentadas nos parágrafos anteriores, a realização de estudos associados à proposição, comparação, seleção e otimização de protocolos para extração de ácidos nucleicos em diferentes espécies tem sido reportada na literatura (OLIVEIRA et al., 2015; MATOS-OLIVEIRA et al., 2017; DIAS et al., 2018). Porém, para a algaroba, estudos de estabelecimento de protocolo e seleção de iniciadores ainda são incipientes. Diante do exposto, objetivou-se comparar a eficiência na extração de DNA genômico de sete protocolos para espécies vegetais em Prosopis juliflora (Sw.) DC.

\section{Material e Métodos}

A coleta das amostras foliares de três espécimes de Prosopis juliflora (Sw.) DC foi realizada no Instituto Federal de Educação, Ciência e Tecnologia Baiano (IF Baiano) em Itapetinga, Bahia, Brasil (coordenadas geográficas: $15^{\circ} 14^{\prime} 38,57^{\prime} \mathrm{S}, 40^{\circ} 13^{\prime} 38,95^{\prime} \mathrm{W}$ ), em um ecótono de Caatinga e floresta estacional decidual e semi-decidual. As amostras encontram-se cadastradas no Sistema Nacional de Gestão do Patrimônio Genético e Conhecimento Tradicional Associado - SisGen (número: AFF0E34).

O material vegetal foi condicionado em isopor com gelo e transferido para o Laboratório de Genética Molecular Aplicada (LGMA) da Universidade Estadual 
do Sudoeste da Bahia (UESB, campus Juvino de Oliveira), no município de Itapetinga, Bahia, onde foi armazenado em freezer $-18^{\circ} \mathrm{C}$ e, posteriormente, foram realizadas as extrações do DNA.

Os testes de extração de DNA genômico foram realizados de acordo com sete protocolos previamente publicados, com modificações apresentadas na Tabela 1. Para todos os protocolos foram realizadas três extrações em duplicata. A maceração das folhas prosseguiu-se de $0,4 \mathrm{~g}$ de tecido foliar e $3 \mathrm{~mL}$ de solução tampão referente a cada protocolo, sendo conduzido com auxílio de almofariz e pistilo em temperatura ambiente até total rompimento das estruturas foliares. Portanto não houve adição de nitrogênio líquido, $\beta$-mercaptoetanol, proteinase K e RNAses em nenhum dos protocolos, respectivamente. As padronizações do material genômico foram obtidas por meio da ressuspensão em $60 \mu \mathrm{L}$ de água ultrapura (q.s.p.).

Os ácidos nucleicos foram quantificados por espectrofotometria nas razões de absorbância em ng/ $\mu \mathrm{L}$ a $\mathrm{A}_{260 / 230}$ e $\mathrm{A}_{260 / 280}$, utilizando o BioDrop ${ }^{\circledR} \mu L I T E$ (Whitehead Scientific). Para melhor atribuição dos resultados, as amostras foram avaliadas também em gel de agarose a $1 \%(\mathrm{~m} / \mathrm{v})$ corado com GelRed $\mathbb{}$ (Biotium) e corrida em solução TBE 0,5X (Tris-Ácido
Bórico-EDTA) durante $90 \mathrm{~min}$ a $90 \mathrm{~V}$. Os resultados foram comparados com o marcador de peso molecular (DNA Lambda; Invitrogen) nas concentrações de $25 \mathrm{e}$ $75 \mathrm{ng} / \mu \mathrm{L}$. O gel foi visualizado em luz UV e registrado em sistema de fotodocumentação Kodak (KODAK MI Software). De posse das leituras espectrofotométricas, mensurou-se as médias e o desvio-padrão com o auxílio do Software BioEstat ${ }^{\circledR}$ 5.0 (AYRES et al., 2007).

Para avaliar a qualidade e a viabilidade de uso do DNA, eles foram submetidos à amplificação por PCR (Polymerase Chain Reaction), utilizando o marcador molecular tipo ISSR (Inter Simple Sequence Repeats) DiCA3'RG (5'- CAC ACA CAC ACA CAC ARG-3'). As amplificações foram realizadas com a seguinte programação: 1) desnaturação: 5 minutos a $94^{\circ} \mathrm{C}$; 2) 35 ciclos: desnaturação - 50 segundos a $94^{\circ} \mathrm{C}$; anelamento - 50 segundos a $48^{\circ} \mathrm{C}$ e extensão -1 minuto a $72^{\circ} \mathrm{C}$; e 3) extensão final: 5 minutos a $72^{\circ} \mathrm{C}$. Os padrões de amplificação foram avaliados por eletroforese a 120 minutos sob uma corrente elétrica de $120 \mathrm{~V}$ em gel de agarose a $2 \%(\mathrm{~m} / \mathrm{v})$ com solução de corrida TBE $0,5 \mathrm{X}$ (Tris-Ácido Bórico-EDTA). As amplificações foram comparadas com o marcador tamanho (1 kb plus; Invitrogen) e os resultados visualizados e registrados conforme acima descrito.

TABELA 1: Descrição dos protocolos utilizados para os testes de extração de DNA genômico de Prosopis juliflora (Sw.) DC.

\begin{tabular}{|c|c|c|c|}
\hline Protocolos & Referências & Tampão de Extração & Modificações \\
\hline $\mathrm{P} 1$ & Sunnucks e Hales (1996) & SDS* $10 \%$ & Proteinase K \\
\hline $\mathrm{P} 2$ & Doyle e Doyle (1990) & $\mathrm{CTAB}^{* *} 5 \%$ & $\begin{array}{l}\text { Nitrogênio líquido, } \\
\beta \text {-mercaptoetanol, RNAse }\end{array}$ \\
\hline P3 & $\begin{array}{c}\text { Método modificado por Štorchová } \\
\text { et al. }(2000)\end{array}$ & Sorbitol & $\beta$-mercaptoetanol \\
\hline P4 & $\begin{array}{l}\text { Método modificado por } \\
\text { Russell et al. (2010) }\end{array}$ & CTAB* $* 3 \%$ e Sorbitol & $\begin{array}{c}\text { Nitrogênio líquido, } \\
\beta \text {-mercaptoetanol, RNAse }\end{array}$ \\
\hline P5 & Mogg e Bond (2003) & SDS* $0,7 \%$ e $\mathrm{NaCl} 500 \mathrm{mM}$ & Proteinase K e RNAse \\
\hline P6 & Barnwell et al. (1998) & CTAB 2\% & Nitrogênio líquido \\
\hline P7 & $\begin{array}{l}\text { Método modificado por } \\
\text { Silva et al. (2014) }\end{array}$ & $\mathrm{CTAB}^{*} * 2 \%$ e $\mathrm{NaCl} 1,4 \mathrm{M}$ & $\begin{array}{c}\text { Nitrogênio líquido, } \\
\beta \text {-mercaptoetanol, RNAse, } \\
\text { Proteinase K }\end{array}$ \\
\hline
\end{tabular}

* Sodium Dodecyl Sulfate. ** Cetyl Trimethylammonium Bromide. Modificações: Reagentes não utilizados no referido protocolo de extração. 


\section{Resultados}

O DNA genômico da espécie Prosopis juliflora (Sw.) DC apresentou pureza média de $0,56^{ \pm 0,17} \mathrm{~A}_{260} / \mathrm{A}_{230}$ e 1,16 ${ }^{ \pm 0,15} \mathrm{~A}_{260} / \mathrm{A}_{280}$ (Tabela 2).

Os protocolos P1, P2 e P4 (SDS 10\%, CTAB $5 \%$ e CTAB 3\% e Sorbitol) apresentaram melhores performances para a espécie, sendo que o tampão SDS $10 \%$ e o CTAB $5 \%$ apresentaram boa concentração de DNA (312 e $321 \mathrm{ng} / \mu \mathrm{L}$ ), porém com alto teor de contaminantes. Já o CTAB 3\% e Sorbitol apresentou menor quantidade de DNA $(123 \mathrm{ng} / \mu \mathrm{L})$, mas se destacou em nível de pureza. Dos testes, o protocolo P6 (CTAB $2 \%$ ) apresentou-se menos eficiente.
Conforme os resultados observados com a eletroforese, foi possível identificar diferença na eficiência da extração de DNA genômico de P. juliflora entre os protocolos (Figura 1).

A partir dos resultados observados para os protocolos P1 (SDS 10\%), P2 (CTAB 5\%) e P4 (CTAB $3 \%$ e Sorbitol), foi possível verificar, a despeito dos valores de baixa pureza estimada a partir de todos os protocolos, a presença de marcas (DNA) definidas, as quais não foram observadas nos demais protocolos. $\mathrm{Na}$ amplificação com o marcador tipo ISSR, (CA)8RG, observou-se a eficiência dos protocolos P1 (SDS 10\%), P2 (CTAB5\%) e P4 (CTAB 3\% e Sorbitol), o que confirma o sucesso desses protocolos para a extração de DNA (Figura 2).

TABELA 2: Quantificação e pureza de DNA genômico de Prosopis juliflora (Sw.) DC a partir das absorbâncias obtidas por espectrofotômetro.

\begin{tabular}{c|ccc}
\hline Protocolos & $\begin{array}{c}\mathbf{A}_{260} / \mathbf{A}_{230} \\
\text { Média }^{ \pm d \mathbf{p}^{*}}\end{array}$ & $\begin{array}{c}\mathbf{A}_{260} \mathbf{A}_{280} \\
\text { Média }^{ \pm d \mathbf{p}^{*}}\end{array}$ & $\begin{array}{c}\text { Concentração (ng/ } \mathbf{\mu L}) \\
\text { Média }^{ \pm d \mathbf{p}^{*}}\end{array}$ \\
\hline P1 & $0,421^{ \pm 0,154}$ & $1,191^{ \pm 0,353}$ & $312,25^{ \pm 152,69}$ \\
P2 & $0,808^{ \pm 0,204}$ & $1,343^{ \pm 0,170}$ & $321,333^{ \pm 118,88}$ \\
P3 & $0,399^{ \pm 0,044}$ & $1,298^{ \pm 0,073}$ & $415,400^{ \pm 252,55}$ \\
P4 & $1,344^{ \pm 0,341}$ & $1,759^{ \pm 0,041}$ & $123,655^{ \pm 71,89}$ \\
P5 & $0,295^{ \pm 0,080}$ & $0,965^{ \pm 0,176}$ & $130,482^{ \pm 110,84}$ \\
P6 & $0,220^{ \pm 0,143}$ & $0,440^{ \pm 0,169}$ & $48,635^{ \pm 12,375}$ \\
P7 & $0,476^{ \pm 0,257}$ & $1,155^{ \pm 0,119}$ & $263,417^{ \pm 168,39}$ \\
\hline
\end{tabular}

dp*: Desvio Padrão.

FIGURA 1: DNA genômico de Prosopis juliflora (Sw.) DC obtido a partir dos protocolos de extração.

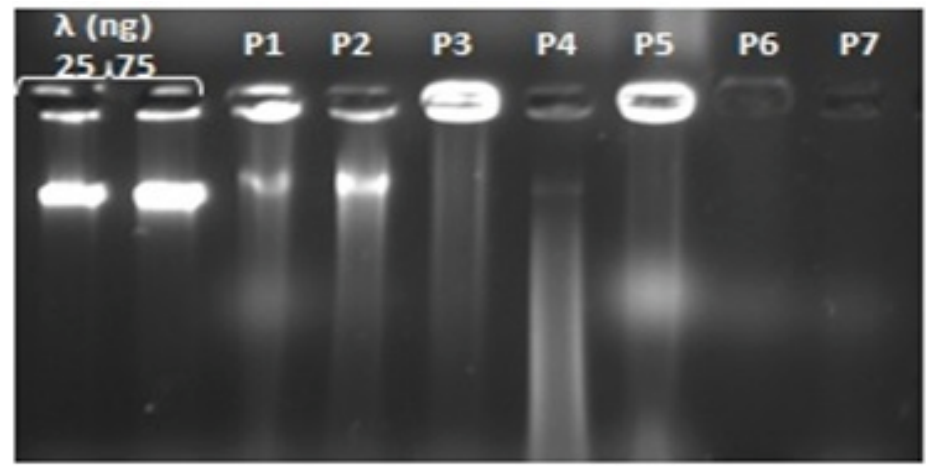

* $\lambda$ - DNA Lambda nas concentrações de 25 e $75 \mathrm{ng} / \mu \mathrm{L}$. 
FIGURA 2: Padrão de amplificação dos fragmentos de DNA genômico de Prosopis juliflora (Sw.) DC obtidos por meio de sete protocolos de extração avaliados com o iniciador ISSR - 5' (CA) RG 3'.

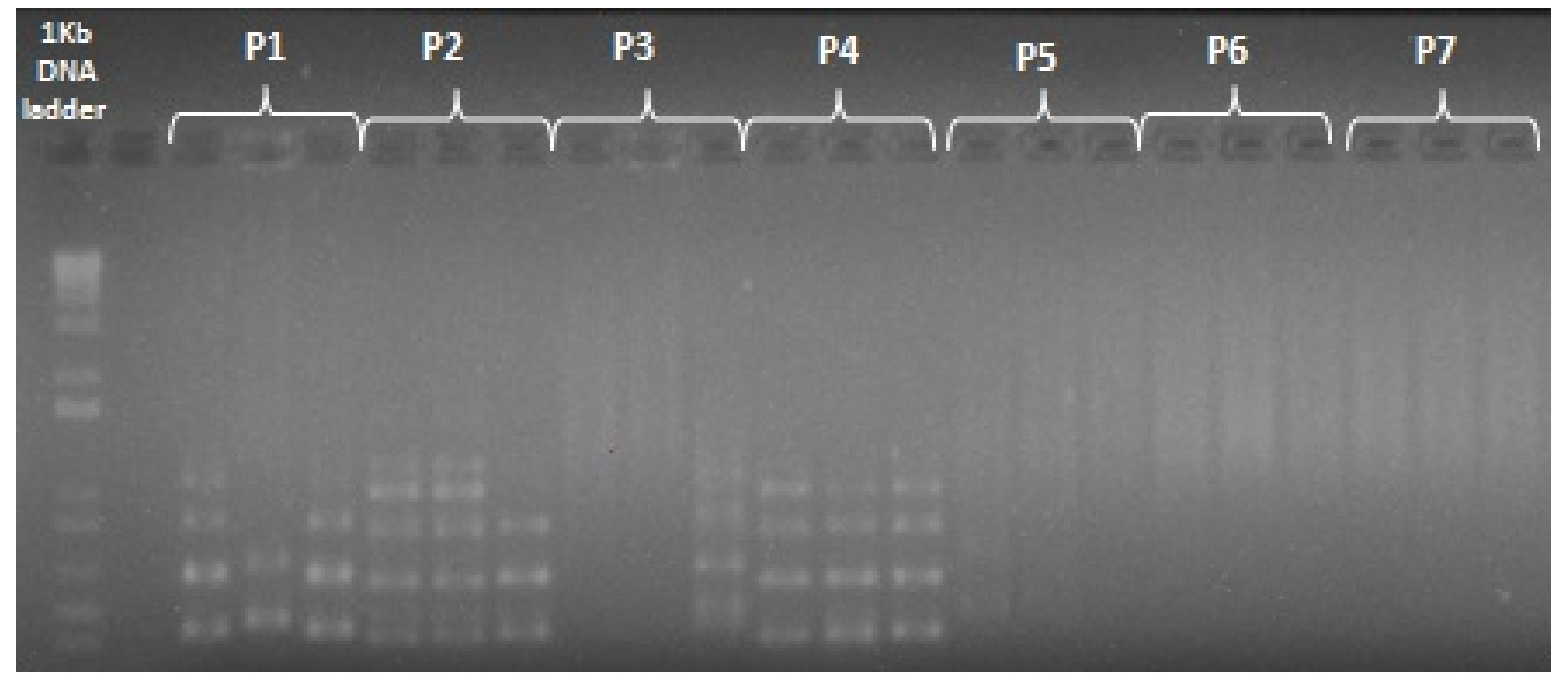

$* 1 \mathrm{~kb}$ DNA Ladder.

\section{Discussão}

Para que o DNA seja considerado puro, ele deve apresentar uma razão de absorbância $\mathrm{A}_{260} / \mathrm{A}_{280}$ média de 1,8 (NELSON; COX, 2004), o que de fato não ocorreu nas extrações realizadas (cujas razões de absorbância média $\mathrm{A}_{260} / \mathrm{A}_{280}$ variaram de 0,44 a 1,76 ). O mesmo foi observado para a quantificação, pois, para amostras isentas de RNA, esperavam-se valores $A_{260} / A_{280}$ entre 1,8 e 2,0, sendo o valor obtido abaixo do esperado para todos os protocolos. Esse fato pode ser explicado pela ausência de RNAse nos protocolos. Em relação à absorbância $A_{260} / A_{230}$, que é um indicador secundário de pureza do DNA, seus resultados inferem a presença de fenol e clorofórmio e de acordo as especificações do fabricante do BioDrop ${ }^{\circledR} \mu L I T E$, para considerar o DNA "puro", os valores desta absorbância devem estar entre 2,0 e 2,2. Ademais, é sabido que o gênero Prosopis inclui árvores com altos níveis de polissacarídeos, compostos fenólicos e outros constituintes químicos (RATHORE, 2009), sendo provável que tais compostos secundários tenham relação direta com os baixos valores observados para as razões $\left(\mathrm{A}_{260} / \mathrm{A}_{230}\right)$ de absorbância.

A obtenção de DNA de boa qualidade tem impacto direto sobre os resultados de técnicas como a reação em cadeia da polimerase (PCR). Sendo que os procedimentos de extração de DNA devem proporcionar uma eficiente lise das células para liberação dos nucleotídeos e uma adequada remoção de proteínas, restos celulares e de organelas. Na amplificação do DNA com o marcador tipo ISSR, a principal vantagem observada para os procedimentos foi a ausência de nitrogênio líquido e do $\beta$-mercaptoetanol. Os quais conferiram baixo custo e maior segurança operacional, uma vez que esse último reagente é tóxico e acarreta vários prejuízos à saúde humana. $\mathrm{O} \beta$-mercaptoetanol se caracteriza por ser um antioxidante muito utilizado em protocolos de extração do DNA genômico em plantas (AUSUBEL et al., 2005). Entretanto, sua remoção não inviabilizou a extração de DNA em quantidade e qualidade necessárias para uso em reação de PCR quando se utilizou os protocolos com tampão CTAB5\%, CTAB 3\% e Sorbitol. Outros estudos corroboram esses resultados, demostrando não haver necessidade da utilização do $\beta$-mercaptoetanol na extração de DNA (SCHMITT et al., 2014; SILVA et al., 2014).

A utilização de nitrogênio líquido no processo de extração de DNA possibilita uma melhor neutralização enzimática e favorece o rompimento do envoltório celular. Em contrapartida, sua utilização eleva os custos do procedimento. No presente estudo, a ausência de nitrogênio líquido não foi determinante para a qualidade e quantidade do DNA extraído, os quais apresentaram resultados satisfatórios para utilização em plataforma 
de PCR. Outros estudos reportaram que a ausência de nitrogênio líquido no processo de maceração torna custo operacional menos oneroso (MICHEL-LÓPEZ et al., 2013; DOS SANTOS; ARAÚJO, 2017).

Os resultados apresentados possibilitaram a seleção de três dos protocolos de extração de DNA genômico: SDS10\%, CTAB5\% puro e CTAB 3\% com Sorbitol. Esses métodos foram propostos por Sunnucks e Hales (1996), Doyle e Doyle (1990) e por Russell et al. (2010). Por fim, este estudo certifica que a utilização desses protocolos com adaptações metodológicas reduz os insumos nocivos à saúde humana e o custo elevado, podendo ser utilizados em estudos de diversidade genética de Prosopis juliflora (Sw.) DC.

\section{Agradecimentos}

Aos órgãos de fomento à pesquisa: CNPq, CAPES, pela concessão das bolsas de doutoramentos; à FAPESB, pelo apoio financeiro referente ao Projeto de Intra PIE 0014/2016, e aos Programa de Pós-Graduação em Zootecnia e Ciências Ambientais da UESB - Campus Itapetinga, pela possibilidade da pesquisa e estrutura física.

\section{Referências}

AHIRWAL, J.; MAITI, S. K.; REDDY, M. S. Development of carbon, nitrogen and phosphate stocks of reclaimed coal mine soil within 8 years after forestation with Prosopis juliflora (Sw.) Dc. Catena, Amsterdam, v. 156, p. 42-50, 2017.

AUSUBEL, F.; BRENT, R.; KINGSTON, R.; MOORE, D.; SEIDMAN, J.; SMITH, J.; STRUHL, K. Current Protocols in Molecular Biology, tomo 1-4. New York: Greene \& John Wiley, 2005. $4.648 \mathrm{p}$.

AYRES, M.; AYRES, M. J.; AYRES, D. L.; SANTOS, S. A. Bioestat 5.0: aplicações estatísticas nas áreas das Ciências Biomédicas. Belém: Mamirauá/CNPq, 2007. 380 p.

BARNWELL, P.; BLANCHARD, A. N.; BRYANT, J. A.; SMIRNOFF, N.; WEIR, A. F. Isolation of DNA from the highly mucilagenous succulent plant shape Sedum telephium. Plant Molecular Biology Reporter, New York, v. 16, n. 2, p. 133-133, 1998.

BESSEGA, C.; POMETTI, C.; LÓPEZ, R. P.; LARREAALCÁZAR, D.; FORTUNATO, R. H.; SAIDMAN, B.; VILARDI, J. C. Genetic diversity and differentiation among Prosopis alba (Leguminosae) populations from dry valleys of Bolivia with different levels of human disturbance and altitude. Ecology and Evolution, Sheffield, v. 8, n. 22, p. 11309-11321, 2018.

DA ROCHA, V. D.; ZÓRTEA, K. E. M.; CARDOSO, E. S.; BISPO, R. B.; TIAGO, A. V.; ROSSI, A. A. B. Efeito da idade da folha na qualidade do DNA extraído de Piper aduncum L. Revista de Ciências Agroambientais, Alta Floresta, v. 15, n. 2, p. 218-222, 2017.

DHIVYA, K.; VENGATESWARI, G.; ARUNTHIRUMENI, M.; KARTHI, S.; SENTHIL-NATHAN, S.; SHIVAKUMAR, M. S. Bioprospecting of Prosopis juliflora (Sw.) DC seed pod extract effect on antioxidant and immune system of Spodoptera litura (Lepidoptera: Noctuidae). Physiological and Molecular Plant Pathology, East Lansing, v. 101, p. 45-53, 2018.

DIAS, C. S.; SANTOS, L. H. T.; LIMA, J. C.; SOARES, A. B. L.; SANTOS, E. S. L.; CERQUEIRA-SILVA, C. B. M. Comparação de protocolos para extração de DNA genômico de Calotropis procera Ait. R. Br. (Apocynaceae: Asclepiadoideae). Multi-Science Journal, Urataí, v. 1, n. 13, p. 277-281, 2018.

DOS SANTOS, E. M.; ARAÚJO, R. R. Testes de comparação de protocolos de extração de DNA e de maceração de tecido de Platonia insignis Mart. (Clusiaceae). Revista Brasileira de Biociências, Porto Alegre, v. 15, n. 4, p. 199-202, 2017.

DOS SANTOS, J. P. S.; DIODATO, M. A. Histórico da implementação da algaroba no Rio Grande do Norte. Pesquisa Florestal Brasileira, Colombo, v. 37, n. 90, p. 201-212, 2017.

DOYLE, J. J.; DOYLE, J. L. Isolation of plant DNA from fresh tissue. Focus, Gaithesburg, v. 12, p. 13-15, 1990.

FALEIRO, F. G.; AMABILE, R. F.; SILVA, C. B. M. C. Marcadores moleculares aplicados ao melhoramento genético de plantas. In: AMABILE, R. F.; VILELA, M. S.; PEIXOTO, J. R. (Ed.). Melhoramento de plantas: variabilidade genética, ferramentas e mercado. Brasília: Sociedade Brasileira de Melhoramento de Plantas, 2018. p. 53-76.

HENCIYA, S.; SETURAMAN, P.; JAMES, A. R.; TSAI, Y. H.; NIKAM, R., WU, Y. C.; CHANG, F. R. Biopharmaceutical potentials of Prosopis spp. (Mimosaceae, Leguminosa). Journal of Food and Drug Analysis, Taipé, v. 25, n. 1, p. 187-196, 2017.

LOPES, M. A.; FÁVERO, A. P.; FERREIRA, M. A. J. F.; FALEIRO, F. G.; FOLLE, S. M.; GUIMARÃES, E. P. Pré-Melhoramento de plantas. Estado da Arte e experiências de sucesso. Brasilia: Embrapa Informações Tecnologicas, 2011. 614 p.

LPWG - THE LEGUME PHYLOGENY WORKING GROUP. Phylogeny and classification of the Leguminosae. Taxon, Vienna, v. 66, n. 1, p. 44-77, 2017.

MATOS-OLIVEIRA, C. F.; ROCHA S. O.; DIAS, C. S.; SANTOS, E. S. L.; CERQUEIRA-SILVA, C. B. M. Comparação de protocolos parar extração de DNA genômico da espécie Atta sexdens (Hymenoptera: Formicidade). Enciclopédia Biosfera, Goiânia, v. 14, n. 25, p. 66-76, 2017.

MICHEL-LÓPEZ， C. Y.; GONZÁLEZ-MENDOZA， D.; GRIMALDO-JUAREZ, O. Fast protocol for extraction of DNA from Prosopis spp leaves (plant adapted to arid environment) without liquid nitrogen. Genetics and Molecular Research, Waco, v. 12, n. 3, p. 4090-4094, 2013. 
MOGG, R. J.; BOND, J. M. A cheap, reliable and rapid method of extracting high-quality DNA from plants. Molecular Ecology Notes, Weinheim, v. 3, n. 4, p. 666-668, 2003.

NELSON, D. L.; COX, M. M. Lehninger, Principles of Biochemistry. New York: Worth Publishers, 2004. 1.119 p.

OLIVEIRA, L. C.; RODRIGUES, D. P.; HOPKINS, M. J. G. The effects of leaf age on the quality of DNA extracted from Parkia R. Br. (Fabaceae) occurring in the Central Amazon. Scientia Amazonia, Manaus, v. 6, n. 2, p. 22-28, 2017.

OLIVEIRA, R. R.; VIANA, A. J. C.; REÁTEGUI, A. C. E.; VINCENTZ, M. G. A. An efficient method for simultaneous extraction of high-quality RNA and DNA from various plant tissues. Genetics and Molecular Research, Waco, v. 14, p. 1882818838, 2015.

RATHORE, M. Nutrient content of important fruit trees from arid zone of Rajasthan. Journal of Horticulture and Forestry, Warrensburg, v. 1, n. 7, p. 103-108, 2009.

RUSSELL, A.; SAMUEL, R.; RUPP, B. E.; BARFUSS, M. H. J.; ŠAFRAN, M.; BESENDORFER, V.; CHASE, M. W. Phylogenetics and cytology of a pantropical orchid genus Polystachya (Polystachyinae, Vandeae, Orchidaceae): evidence from plastid DNA sequence data. Taxon, Vienna, v. 59, n. 2, p. 389-404, 2010.
SCHMITT, K. F. M.; SILVA, B. M.; ROSSI, A. A. B.; SANDER, N.; SILVA, C. J. Estabelecimento e otimização de protocolo para extração e amplificação de DNA em tecido foliar de Curcuma longa (L). Enciclopédia Biosfera, Goiânia, v. 10, n. 18, p. 1560-1568, 2014.

SILVA, B. M.; DALBOSCO, E. Z.; BOTINI, N.; FARIA, R. B.; ROSSI, A. A. B. Protocolo para extração de dna genômico de Anacardium giganteum W. Hancock Ex Engl. (Anacardiaceae). Enciclopédia Biosfera, Goiânia, v. 10, n. 19, p. 2401, 2014.

ŠTORCHOVÁ, H.; HRDLIKOVÁ, R.; CHRTEK, J.; TETERA, M.; FITZE, D.; FEHRER, J. An improved method of DNA isolation from plants collected in the field and conserved in saturated $\mathrm{NaCl}$ / CTAB solution. Taxon, Vienna, v. 49, n. 1, p. 79-84, 2000.

SUNNUCKS, P.; HALES, D. F. Numerous transposed sequences of mitochondrial cytochrome oxidase I-II in aphids of the genus Sitobion (Hemiptera: Aphididae). Molecular Biology and Evolution, Oxford, v. 13, n. 3, p. 510-524, 1996. 